\title{
Inhibition of MAPK Hog1 Results in Increased Hsp104 Aggregate Formation Probably through Elevated Arsenite Influx into the Cells, an Approach with Numerous Potential Applications
}

\author{
Doryaneh Ahmadpour ${ }^{*}$, Amin A. Banaeiyan'1, Morten Grøtli ${ }^{2}$, Martin Adiels ${ }^{3}$, \\ Mattias Goksör'1, Caroline B. Adiels ${ }^{1}$ \\ ${ }^{1}$ Department of Physics, University of Gothenburg, Gothenburg, Sweden \\ ${ }^{2}$ Department of Chemistry and Molecular Biology, University of Gothenburg, Gothenburg, Sweden \\ ${ }^{3}$ Department of Mathematical Sciences, University of Gothenburg, Gothenburg, Sweden \\ Email: doryaneh.ahmadpour@physics.gu.se
}

Received 25 December 2013; revised 23 January 2014; accepted 20 February 2014

Copyright (C) 2014 by authors and Scientific Research Publishing Inc.

This work is licensed under the Creative Commons Attribution International License (CC BY).

http://creativecommons.org/licenses/by/4.0/

(c) (i) Open Access

\begin{abstract}
Arsenic is a highly toxic and carcinogenic metalloid widely dispersed in the environment, contaminating water and soil and accumulating in crops. Paradoxically, arsenic is also part of modern therapy and employed in treating numerous ailments and diseases. Hence, inventing strategies to tune cellular arsenic uptake based on purpose is striking. Here, we describe an approach in which the arsenite uptake can be increased using a MAPK inhibitor. Employing microfluidic flow chambers in combination with optical tweezers and fluorescent microscopy, we elevated the influx of arsenite into the yeast Saccharomyces cerevisiae cells following short-term treatment with a Hog1 kinase inhibitor. The increase in arsenite uptake was followed on arsenite triggered redistribution of a reporter protein, Hsp104-GFP, which was imaged over time. The effect was even more pronounced when the yeast mother and daughter cells were analyzed disjointedly, an opportunity provided owing to single-cell analysis. Our data firstly provide a strategy to increase arsenite uptake and secondly show that arsenite triggered aggregates, previously shown to be sites of damaged proteins, are distributed asymmetrically and less accumulated in daughter cells. Inventing approaches to tune arsenite uptake has a great value for its use in environmental as well as medical applications.
\end{abstract}

*Corresponding author.

How to cite this paper: Ahmadpour, D., et al. (2014) Inhibition of MAPK Hog1 Results in Increased Hsp104 Aggregate Formation Probably through Elevated Arsenite Influx into the Cells, an Approach with Numerous Potential Applications. American Journal of Molecular Biology, 4, 59-71. http://dx.doi.org/10.4236/ajmb.2014.42008 


\section{Keywords}

\section{Mitogen Activated Protein Kinase (MAPK); Hog1; MAPK inhibitor; Arsenic; Microfluidics}

\section{Introduction}

Arsenic is a toxic metalloid broadly spread in the environment [1] and its concentration is higher than the permissible levels in many regions of the world [2] [3]. Human is usually exposed to arsenic through industrial activities, by drinking water that has percolated through arsenic-rich soil [4] [5] or by consuming arsenic accumulating crops such as rice, wheat, fruits and vegetables [6]. Long-term exposure to arsenic causes a number of human diseases e.g. diabetes [7], kidney and cardiovascular diseases [8]. It is also associated with liver, lung, skin and bladder cancers [9]. Paradoxically, arsenic compounds have a history of over 2000 years of use as medicine [10]. In particular, it is used in the treatment of diseases caused by protozoan parasites [11]. The organic arsenical Melarsoprol is used as first line treatment against late stage human African trypanosomiasis [12] [13]. Arsenic trioxide is also the active ingredient in the chemotherapeutic drug Trisenox ${ }^{\circledR}$, which is used for the treatment of acute promyelocytic leukaemia [14] [15]. Arsenic trioxide also shows high cytotoxic effect in small cell lung carcinoma, which otherwise responds very poorly to treatments [16]. Similarly, it has recently been shown that arsenic can be a choice of therapy for treating other forms of cancer [10] [17]. However, the efficiency of response to arsenic-based drugs depends partly on the levels of cellular arsenic uptake [18]. Hence, in order to produce safe crops with low arsenic accumulation, to gain a more effective therapy when the cancer cells or parasites show resistance to arsenic-based drugs and to engineer arsenic accumulating plants for phytoremediation purposes, innovating approaches to tune the uptake of arsenic upon purpose is imperative. Here, we addressed this issue by inventing an approach with which the cellular uptake of arsenite is increased employing a Mitogen Activated Protein Kinase (MAPK) inhibitor.

Arsenic as the trivalent form (arsenite As(III)) is the most prominent and toxic form [1]. In the eukaryotic model organism Saccharomyces cerevisiae (budding yeast), aquaglyceroporin Fps1 is the major entry route for arsenite (As(III)) in the presence of glucose [19]. Aquaglyceroporins have also been indicated as the entry route for As(III) in many other organisms e.g. plants [20], mammals [21], and humans [22]. Moreover, the activity of arsenite influx and detoxification systems is controlled by signaling proteins. In a previous study, we have shown that deleting the gene encoding for the MAPK Hog1 in S. cerevisiae results in arsenite sensitivity due to elevated intracellular arsenite levels and that the increased arsenite influx is dependent on the aquaglyceroporin Fps1 [23]. Further, we provided evidence that MAPK Hog1 is activated upon arsenite exposure. Hog1 phosphorylation then negatively regulates Fps1-mediated arsenite uptake and Hog1 phosphorylation as well as its kinase activity are critical for arsenite tolerance acquisition [23]. Hog1 is the ultimate MAPK of High Osmolarity Glycerol (HOG) pathway in yeast with both cytoplasmic (e.g. Fps1) and nuclear (e.g. Sko1, Hot1, Msn2/4) targets controlling set of different gens in response to hyper-osmotic stress [24]-[26]. However, the most important role of Hog1 in response to hyperosmotic stress concerns the control of glycerol accumulation [24] [27]. Hog1 displays quantitative and qualitative differences in response to hyperosmotic and arsenite stress [23], nevertheless its kinase activity is required in response to both stress conditions [23] [28].

Hitherto, successful genetic modification attempts e.g. deleting the gene encoding for the MAPK of interest [23], constructing kinase dead allele of the MAPK [23] or deleting the terminal domain of aquaglyceroporins [23] have been executed, which result in higher arsenite uptake. However, such modifications may introduce irreversible, compensatory and sometimes detrimental changes to the cells.

The objective of this study was to develop a method to alter the cellular arsenite uptake (probably via Fps1) by employing Hog1 kinase inhibitor in yeast $S$ cerevisiae. The employed Hog1 kinase inhibitor has previously been shown to selectively inhibit Hog1 kinase activity without targeting other MAPKs in S. cerevisiae [29]. The kinase activity of Hog1 is required for the feedback control and down regulation of HOG signaling [30]. Similarly, a kinase dead version of Hog1 shows sustained phosphorylation in response to osmotic stress [30]. The in vivo activity of Hog1 inhibitor has therefore been shown by demonstrating a sustained Hog1 phosphorylation in response to osmotic stress in the presence of Hog1 inhibitor [29]. The effect has also been shown on single cell level through inhibiting the nuclear accumulation of Hog1 upon hyperosmotic stress, which requires its kinase 
activity [29] [31]. In the current study, we have used Hsp104 heat shock protein as readout. Hsp104 is involved in refolding and reactivating denatured, aggregated proteins and is induced in response to different stresses e.g. heat, ethanol, arsenite and long-term storage in the cold [32]. Hsp104 has been shown to be evenly distributed throughout cytosol in unexposed cells. Arsenite exposure leads to protein misfolding, thereby triggering Hsp104-GFP redistribution to distinct foci (aggregates) [33], shown to be sites of protein aggregation [34] [35]. The aggregate formation occurs in an arsenite concentration dependent manner and is supposedly triggered by intracellular As(III) since the arsenite induced Hsp104-GFP foci are absent in the cells over expressing the plasma membrane-localized As(III) efflux pump Acr3 [33]. Although information obtained by traditional methods of molecular biology is absolutely valuable for understanding the ongoing intracellular processes, it is often insufficient and even misleading as the existing cell-to-cell variation is neglected. These variations may rise from intrinsic (e.g. variations in gene expression level) or extrinsic (e.g. difference in cell cycle stage) origins. Therefore, we addressed the objective of this study at single cell level to count for such existing cell-to-cell variations. Here, using an interdisciplinary approach, which merges biology and physics we have used a fluorescence microscope platform combining microfluidics and optical tweezers. This experimental setup allows switching the cellular environment within seconds, which is otherwise a poor temporal resolution procedure at population level. It allows monitoring the response of individual cells over time using real-time microscopy imaging and high content cell screening in a microfluidic device in an automated manner. Moreover, it allows screening for various inhibitors at diminutive quantity. This platform has previously been used to provide detailed information regarding vital aspects of cellular behavior, such as cell signaling and stress response [36]-[42].

\section{Materials and Methods}

\subsection{Yeast Strain and Cell Preparation Procedures}

Sacharomyces cerevisiae strain HSP104-GFP (BY4741HSP104-GFP-HIS3-MX6) (Invitrogen) cells were grown in Yeast Nitrogen Base (YNB, $6.7 \mathrm{~g} / \mathrm{l}$ ) with Complete Supplement Mixture (CSM, $1.54 \mathrm{~g} / \mathrm{l}$ ) and 2\% glucose (pH $=6)$, at $30^{\circ} \mathrm{C}$ on a shaker $(220 \mathrm{rpm})$. The cells were collected at $\mathrm{OD}_{600}=0.6-1.0$.

\subsection{Inhibitor and Sodium Arsenite}

The selective Hog1 inhibitor 4-(1-benzyl-4-phenyl-1H-1,2,3-triazol-5-yl)-N-isopropylpyridin-2-amine ( $\mathrm{M}=$ $478.67 \mathrm{~g} / \mathrm{mol}$ ) [29] [31] was dissolved in dimethyl sulfoxide (DMSO) to a final concentration of $1.9 \mathrm{mM}$ stock solution. The final inhibitor concentration in YNB was $10 \mu \mathrm{m}$ and incubation time was set to 5 minutes.

Sodium arsenite $\left(\mathrm{NaAsO}_{2}\right)$ (Sigma-Aldrich) was dissolved in water prior to use and applied to a final concentration of $0.1 \mathrm{mM}$ in YNB.

\subsection{Microfluidics and Microscopy}

The microfluidic device was fabricated using soft lithography as previously described [31] [43]. Just prior the experiment, glass syringes (Hamilton Company) containing the cells and different media respectively were attached to the four-inlet microfluidic flow chamber via polytetrafluoro ethylene tubings (Cole-Parmer, Vernon Hills, IL, USA). Using a fiber-coupled ytterbium laser (YLD-5-LP, IPG Photonics) with a wavelength of 1070 $\mathrm{nm}$ and estimated power of $240 \mathrm{~mW}$ in the laser focus [39], single cells were trapped and moved from the flow of the cell inlet channel. One by one, cells were then gently pressed against the bottom of the system to adhere and form a $5 \times 5$ cell array. The trapping procedure limited the cells exposure to the infrared light only for a few seconds ( $<10 \mathrm{~s})$ to ensure minimized photo damage [44] [45]. The location of the cell array $(120 \mu \mathrm{m},-10 \mu \mathrm{m})$ and the flow rates were determined by simulations of the velocity profiles and the concentration gradients in the system based on the diffusion coefficients of the fluids (Figures 1(a) and (b)) to ensure that cells are not subjected to any substrate gradients but are fully covered by the specific treatment. Microenvironmental changes necessary for monitoring the Hsp104-GFP redistribution (aggregate formation), were created by changing the flow rates in the inlet channels (5, 5, 500 and $1000 \mathrm{~nL} / \mathrm{min}$ for channels " 1 ", "2", "3" and " 4 ", respectively) set by the syringe pumps (CMA 400, CMA Microanalysis). In this way, the environment could rapidly be changed from neutral media to a media containing Hog1 inhibitor, and thereafter to a media containing arsenite. The customwritten automation software in Open Lab (PerkinElmer, Waltham, MA, USA) used for trapping and positioning the 


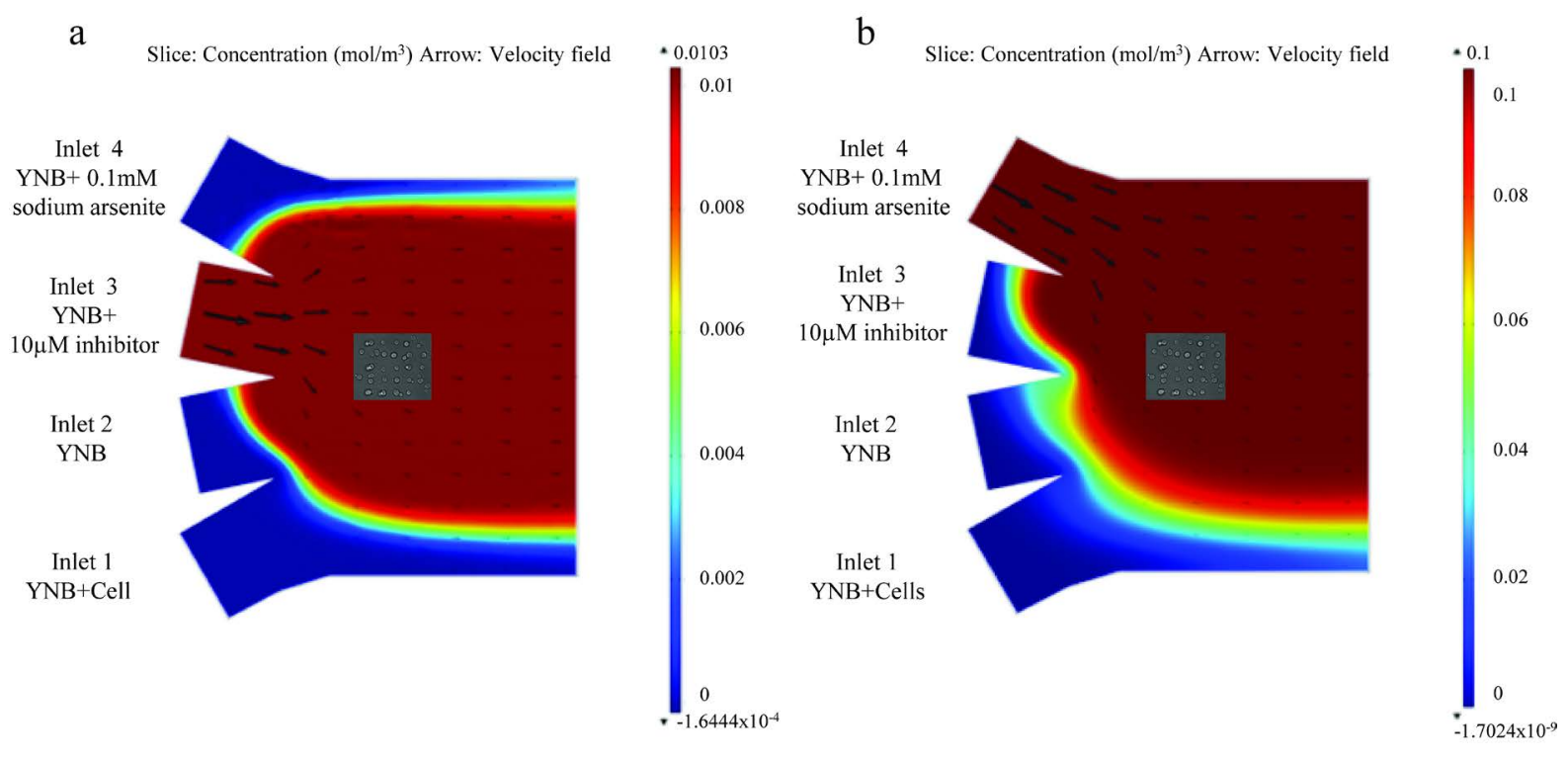

Figure 1. Simulation results for Hog1 inhibitor and arsenite in four-inlet microfluidic flow chamber. (a) Simulation results for the Hog1 inhibitor $(10 \mu \mathrm{m})$ incubation in the microfluidic chamber. The flows in inlet channels $1-4$ are set to 5, 5, 500 and $5 \mathrm{nl} / \mathrm{min}$ respectively. Diffusion coefficient of the inhibitor is $2.4 \times 10^{-10} \mathrm{~m}^{2} / \mathrm{s}$. The color legend illustrates the concentration of the substance and arrows show the velocity field inside the microfluidic channels. (b) Simulation results for the arsenite $(0.1 \mathrm{mM})$ treatment in the microfluidic chamber. The flows in inlet channels $1-4$ are set to $5,5,5$ and $1000 \mathrm{nl} / \mathrm{min}$ respectively. Diffusion coefficient of sodium arsenite is $1.21 \times 10^{-9} \mathrm{~m}^{2} / \mathrm{s}$. The color legend illustrates the concentration of the substance and arrows show the velocity field inside the microfluidic channels.

cells as well as controlling the syringe pumps, the microscope and the EM-CCD camera (C9100-12, Hamamatsu Photonics) used for the image acquisition, enabled an automated setup and maximized the control of the experimental process. For determining the number of aggregates, cells were imaged as z-stacks with nine focal layers spaced $0.8 \mu \mathrm{m}$ apart. These images were acquired before and every 60 seconds for 5 minutes during inhibitor treatment or before and every 5 minutes for 60 minutes during arsenite treatment. The images were analyzed using CellStress software [46] and statistics were done using non-parametric Kruskal-Wallis tests.

\section{Results and Discussion}

\subsection{Hog1 Kinase Inhibitor Treatment Leads to Elevated Arsenite Induced Hsp104-GFP Redistribution}

To examine whether treating cells with Hog1 kinase inhibitor results in increased arsenite influx into the cells, we compared the arsenite induced aggregate formation as a readout for increase in arsenite influx into the cells [33] in control and inhibitor treated cells. To address this issue, we first established that the condition in microfluidic device in the presence of only growth media does not cause any aggregate formation (Figure 2). We next asked whether the Hog1 kinase inhibitor per se triggers Hsp104-GFP redistribution (aggregate formation). Based on previous study inhibiting Hog1 kinase activity with the applied inhibitor [31], (Hamngren, C. et al., submitted), a range of concentrations between $5 \mu \mathrm{M}$ to $25 \mu \mathrm{M}$ of Hog1 kinase inhibitor and different incubation times were examined, of which the final concentration of $10 \mu \mathrm{M}$ for a period of 5 minutes incubation was chosen as increasing concentration/incubation time could result in false aggregate formation. We monitored Hsp104-GFP relocalization in the cells positioned in the array upon exposure to growth media for 45 minutes after 5 minutes pretreatment with $10 \mu \mathrm{M}$ inhibitor. Our data clearly showed that the applied inhibitor concentration and period of incubation does not promote aggregate formation within the investigated condition and time span (Figure 3(a)). Although the total period of the experiments were initially set to 60 minutes, as some cells showed slight increase in aggregate formation around 50 minutes, the time lapse studies were instead performed to terminate at 45 minutes to avoid any false aggregate formation. The late aggregate formation following incubation with Hog1 inhibitor might be explained by different scenarios. There is a possibility that incubation with the inhibitor 


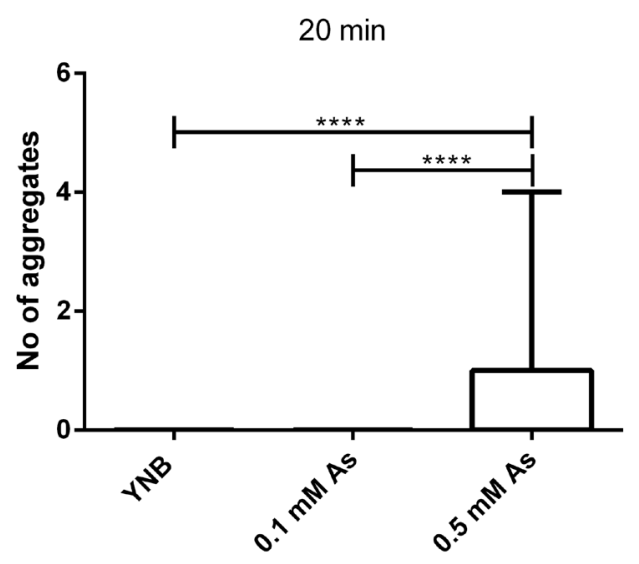

(a)

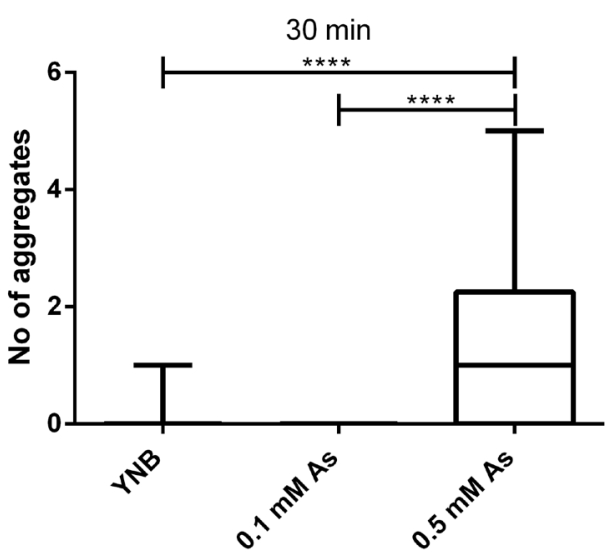

(b)

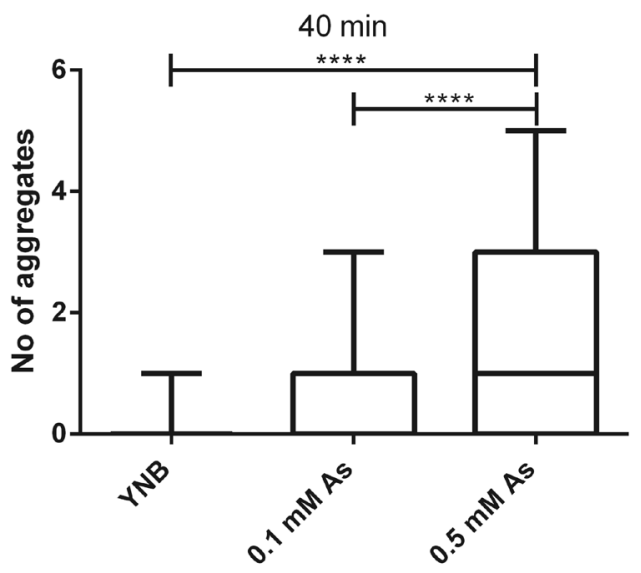

(c)

Figure 2. Arsenite induces aggregate formation in a concentration dependent manner (as shown previously). Number of aggregates per cell upon different treatments; growth media (YNB) (65 cells), $0.1 \mathrm{mM}$ sodium arsenite (As) (46 cells) and $0.5 \mathrm{mM}$ sodium arsenite ( 59 cells) at three time points ((a) 20, (b) 30 and (c) 40 minutes) in a four-inlet microfluidic flow chamber is presented. The aggregates are induced in the presence of arsenite in a concentration dependent manner and displayed in box plots as indicated. Statistics are calculated using non-parametric Kruskal-Wallis tests. $\left({ }^{*}=\mathrm{p}<0.05\right)$.

either directly target the components involved in protein folding or result in stress conditions [32] e.g. oxidative stress [47] that triggers Hsp104 relocalization. The Hog1 inhibitor may also be partly non-specific and hence target other kinases in the cell resulting in eventual protein misfolding and Hsp104 redistribution. However, addressing the specificity of kinase inhibitors in yeast is rather difficult as panels of purified kinases are not commercially available for such screens, whereas available for human kinases [48]. Another likely explanation would be that inhibition of the kinase activity of the Hog1 for a longer time leads to protein misfolding and thereby induction of heat shock protein responses. Hog1 kinase activity has been shown required to provide a necessary function to cope with unfolded protein accumulation due to ER stress [49]. Considering the fact that Hog1 becomes activated upon a wide variety of environmental cues and is involved in transcription, translation, transport, as well as cell cycle adaptations in response to different conditions [23] [24] [29], these are all plausible scenarios. These mechanisms are remained to be explored further in the future studies. However, in order to avoid conceivable synergetic aggregate formation, we have excluded the later time points when the few inhibitor induced aggregates occur.

We next asked if arsenite is efficiently taken up by the cells when introduced in the flow and if it induces quantifiable Hsp104-GFP redistribution (aggregates) as reported before [33] in our setup. To this end, the cell arrays were subjected to the final concentration of $0.1 \mathrm{mM}$ sodium arsenite and the aggregate formation was 
followed by time lapse imaging every 5 minutes for 45 minutes. The results (Figure 3(b)) showed that arsenite is effectively taken up by cells (46 cells), induces Hsp104-GFP relocalization and arsenite induced aggregates were precisely quantifiable with the CellStress software [46]. The arsenite induced aggregate formation initiated roughly at 30 minutes after stress exposure. The maximum number of aggregates per cell found was six, the fraction of the cells showing aggregates after 45 minutes was slightly below 50\% ranging from 1 to 4 aggregates per cell (Figure 3(b)) and the mean value of aggregates per cell was 0.85 (data not shown). As it was described earlier [33] we correlated the number of induced aggregates to the uptake/intracellular level of arsenite. This assumption is bolstered by the fact that the induced aggregates indeed increase by arsenite concentration (Figure 2, [33]) whereas disappear upon over expression of arsenite export pump [33]. Our data also demonstrating that aggregate formation is not induced in normal condition in the presence of growth media (Figure 2) supports that the aggregate formation seen in arsenite-rich condition is likely not due to other stresses such as heat or cold stress but to the fact that the cells reside in arsenite supplemented growth media. However, this assertion could be supplemented and strengthened by traditional arsenite uptake assays. Nonetheless, the arsenite interference with protein folding and consequent aggregate formation does not contradict previously identified arsenite induction of oxidative stress [50] and could also be the case in our experiments.

To address whether the Hog1 kinase inhibitor is able to improve the arsenite uptake, we compared the arsenite induced aggregate formation in terms of increase in the number of cells having aggregates, increase in the number of aggregates per cell and time of initiation of aggregate formation in inhibitor treated and untreated conditions. Cell arrays were exposed to $10 \mu \mathrm{m}$ Hog1 inhibitor for 5 minutes and subsequently to $0.1 \mathrm{mM}$ sodium arsenite for 45 minutes. Images were acquired prior and then every minute during the 5 minutes inhibitor treatment. Subsequently, images were attained every 5 minutes during the arsenite exposure through the end of the time lapse experiment. Interestingly, the arsenite induced aggregate formation following pretreatment with the Hog1 kinase inhibitor initiated earlier (20 minutes compared to 30 minutes). The maximum number of aggregate per cell in this condition reached up to nine (compared to six), the fraction of the cells displaying aggregate formation was about $80 \%$ after 45 minutes (compared to 50\%) (Figure 3(c)) and the mean value of aggregates per cell (of in total 86 cells) was 2.35 times higher ( 2 vs. 0.85 ) (data not shown).

Hence, we concluded that 1) the Hog1 inhibitor does not induce aggregate formation per se in the investigated time span and condition. However, as discussed earlier, the few aggregates formed at later time points might be due to inhibitor interference with protein folding, inhibitor induced stress conditions, the possibility of the inhibitor being non-specific that in the long run could affect protein folding components or a consequence of longterm Hog1 inhibition; 2) the arsenite induced Hsp104-GFP redistribution [33] is reproducible when arsenite is introduced in the flow and is quantifiable in our setup. As previous and current data confirm, the aggregate formation is indeed induced by arsenite, however, the mechanisms of Hsp104-GFP induction upon arsenite exposure has been described elsewhere [33], and most importantly; 3) the short-term Hog1 kinase inhibitor treatment of the cells prior to arsenite treatment results in faster and increased aggregate formation both in terms of number of cells showing aggregate as well as number of aggregates per cell, probably due to the augmented arsenite uptake.

We are the first to provide an approach in which small molecule, cell-permeable, fast acting and highly efficient kinase inhibitor can act as powerful means to significantly (Figure 3(d)) elevate the arsenite induced aggregates supposedly through elevated arsenite influx into the cells without any requirement for introducing genetic modifications. Although, mechanisms behind this effect is not exclusively elucidated and requires further investigations, the current results together with our previous study [23] favors a possible mechanism (Figure 4) in which Fps1is negatively regulated by a kinase activate Hog1 [23]. However, in the presence of the inhibitor the kinase activity of Hog1 is partially impaired, which in turn leads to higher arsenite uptake via Fps1 indicated by higher number of arsenite induced aggregates. This hypothesis could be further evidenced e.g. by applying a truncated version of Fps1 that lacks the N-terminal regulatory domain rendering Fps1 constitutively open [51]. However, other players i.e. the possibility of inhibitor induced aggregate formation or other stress conditions such as oxidative stress induction of Hsp104-GFP relocalization are not ruled out (Figure 4). The fact that increase in arsenite uptake and thereby increase in the number of aggregates is partial is perhaps partly due to the incomplete inhibition of Hog1 [31] and partly due to the other existing arsenite detoxification mechanisms e.g. arsenite export pump Acr3 [52] and/or arsenite-glutathione conjugation and sequestration to the vacuole through the ABC transporter Ycf1 [53] (Figure 4) in the cell. Regardless of the cause, the partial nature of this MAPK inhibition might have advantages as it prevents massive arsenite influx and severe, irreversible damage to the cells. 
a)

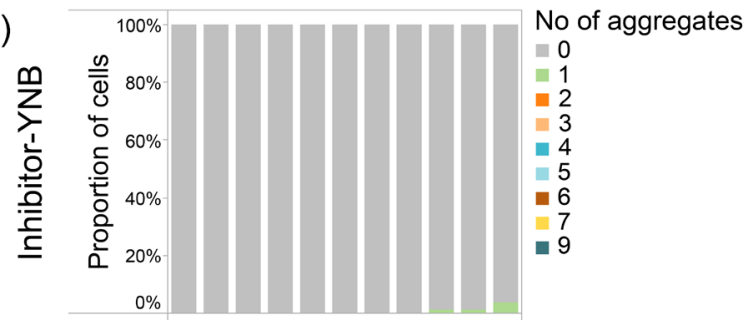

c)

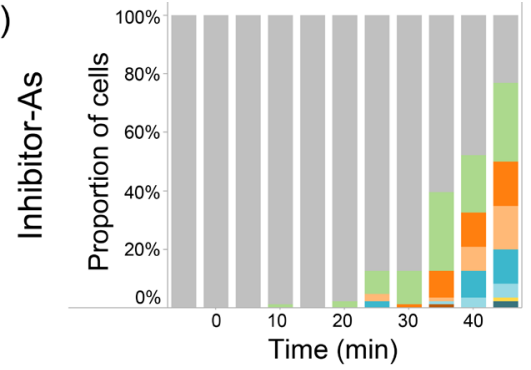

b)

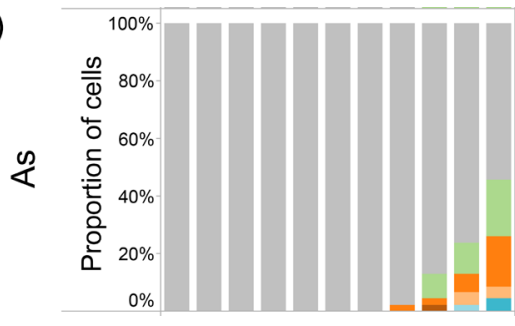

d)

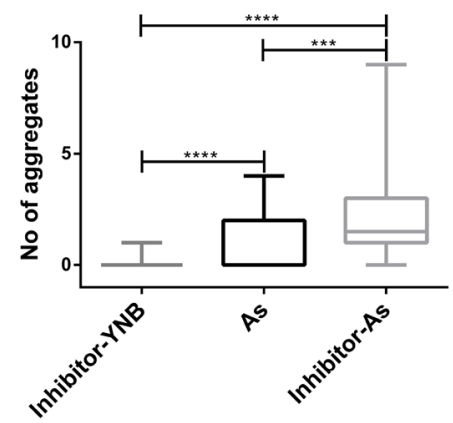

Figure 3. Hog1 kinase inhibitor increases the arsenite induced aggregate. Percentage of cells displaying the distribution of aggregates upon different treatments in a four-inlet microfluidic flow chamber over time. (a) Arrays of cells were treated with $10 \mu \mathrm{M}$ Hog1 kinase inhibitor for 5 minutes. Thereafter, cells were incubated in growth media (Inhibitor-YNB) for 45 minutes. Aggregate formation was not induced under this condition (only 3 aggregates among 82 analyzed cells were induced after 45 minutes). (b) Arrays of cells (46 cells) were treated with $0.1 \mathrm{mM}$ sodium arsenite (As) for 45 minutes. The aggregate formation initiated at 30 minutes and the maximum number of aggregates per cell reached up to 6. Also, the proportion of cells displaying aggregates is increased over time (reaching approximately 50\%). (c) Arrays of cells (86 cells) were treated with 10 $\mu \mathrm{M}$ Hog 1 kinase inhibitor for 5 minutes prior exposure to $0.1 \mathrm{mM}$ sodium arsenite (Inhibitor-As) for $45 \mathrm{mi}-$ nutes. The aggregate formation initiated already at 20 minutes and the maximum number of aggregates per cell reached up to 9 . The proportion of cells displaying aggregates reaches almost $80 \%$ at the final time point. (d) A box plot displaying the number of aggregates per cell formed at 45 minutes in the indicated cell treatments (as explained above). At 45 minutes, comparison using Kruskal-Wallis non-parametric test between the cell responses at all conditions show statistical significance. Already after 25 minutes, there was significant difference between cells treated with inhibitor-As and cells treated with only As (data not shown). $\left({ }^{*}=p<0.05\right)$

\subsection{Arsenite Accumulates to a Higher Degree in Mother Cells Compared to Their Daughters Following Inhibitor Treatment}

The cell-to-cell variation even exists in genetically homogenous populations. These variations may arise from intrinsic (differences in the expression levels of genes in the same cell) or extrinsic (cell-to-cell variation in a population) sources [54] [55]. The latter can partly be explained by fluctuations that occur through different cell cycle stages [56]. Therefore, we asked if the variation in response between mother cells and buds can to some extent explain the cell-to-cell variation in our results. To this end, we discriminated between mother and daughter cells (only attached buds) and examined whether the As(III) induced Hsp104-GFP relocalization (aggregate) shows a bimodal distribution between mother cells and their buds. The results showed no induced aggregate formation in mother cells (54 cells) or buds (28 cells) following inhibitor treatment (Figure 5(a)). Upon arsenite treatment, the number of aggregates was not substantially (Figure 5(d)) different in the mother cells (33 cells) compared to the buds (13 cells) (40\% compared to the $60 \%$ respectively, Figure 5(b)), (mean value of 0.72 compared to 1.1 per cell respectively, data not shown). Whereas, this difference was slightly more pronounced (Figure 5(d)) following kinase inhibitor treatment (mean value of 2.5 vs. 1.2 respectively, data not shown). The fraction of the mother cells (55 cells) showing aggregates compared to the buds ( 31 cells) was $90 \%$ to $60 \%$ respectively and the maximum number of aggregates per cell was also higher in mother cells compared to the buds (9 compared to 5) (Figure 5(c)). More interestingly, the effect of kinase inhibitor treatment in increasing arsenite uptake was much more significant (Figure 5(d)) when it was studied only on discriminated mothers compared to indiscriminated cells (mothers and buds together). While the mean number of aggregates in each mother cell upon exposure to only arsenite was 0.7 the mean number of aggregates per each mother cell upon arsenite 


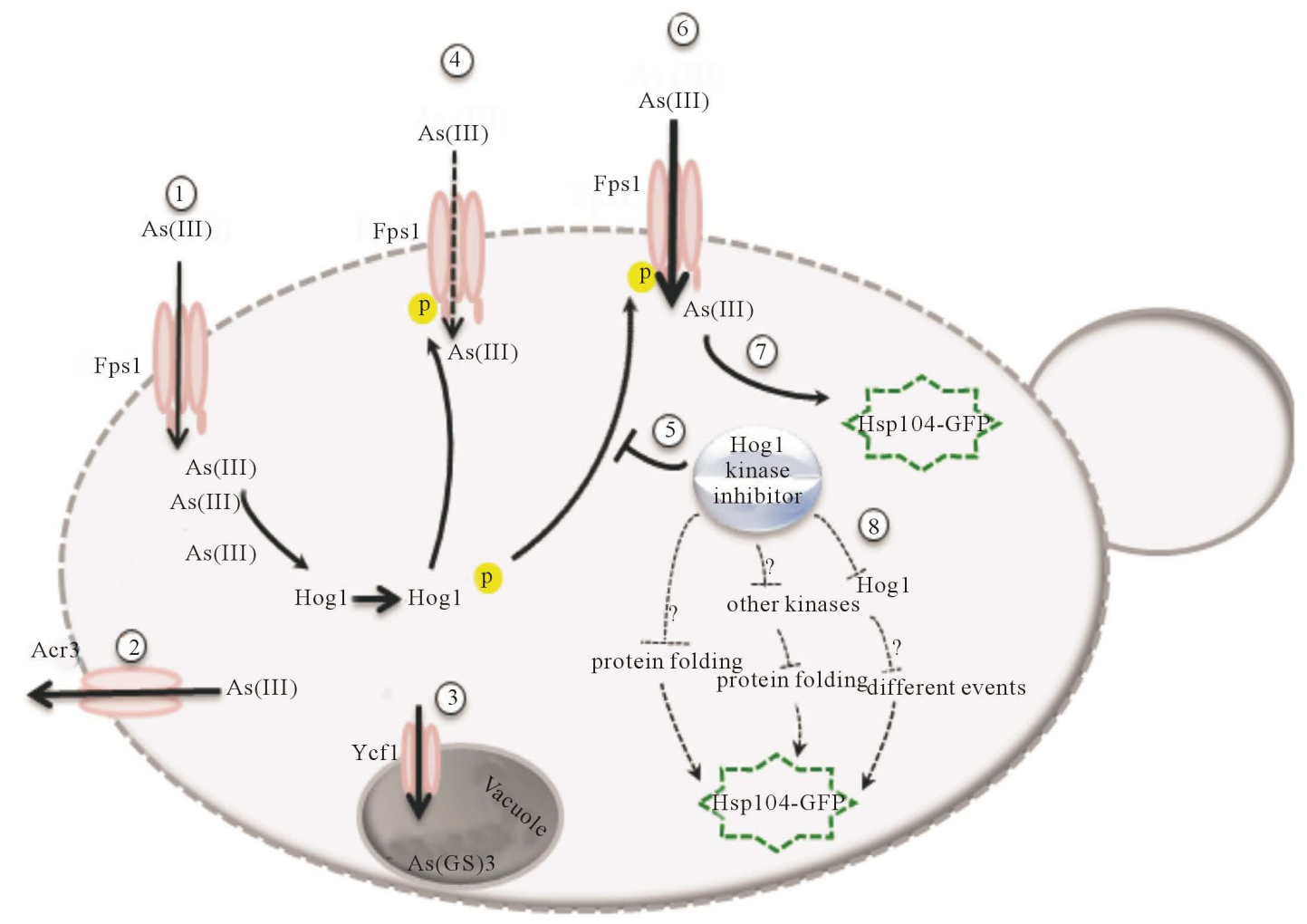

Figure 4. Mechanisms involved in arsenite uptake and tolerance in S. cerevisiae. The uptake of trivalent form of arsenic (arsenite) is mediated by the glycerol channel Fps1 (1). The arsenite is then either extruded from the cell by arsenite export pump Acr3 (2) or conjugates to glutathione and sequesters to the vacuole through the ABC transporter Ycf1 (3). Hog1 is phosphorylated in response to arsenite and negatively modulates Fps1 transport activity perhaps by phosphorylating Fps1 (4). Our results together with previous studies favor a model in which the Hog1 kinase inhibitor impairs the negative regulation of Hog1 on Fps1 (5) thereby increasing the arsenite uptake (6), which leads to increase in Hsp104-GFP redistribution (7). However, the other possible mechanisms involved in redistribution of Hsp104-GFP such as inhibition of proper protein folding, unspecific targeting other kinases leading to Hsp104 redistribution or effects related to long-term inhibition of Hog1 (8) are not ruled out.

treatment post inhibitor exposure was 2.5 (data not shown) proving 3.6 times increase. This significant difference (Figure 5(d)) is very well reflected in the fraction of the mother cells showing aggregates upon arsenite treatment (40\% Figure 5(b)) compared to the mother cells exposed to arsenite following inhibitor treatment (90\% Figure 5(c)). In addition, the maximum number of aggregates following arsenite treatment after 45 minutes reaches up to 4 (Figure 5(b)) whereas upon inhibitor-arsenite exposure the maximum number of aggregates reaches up to 9 aggregates (Figure 5(c)). Collectively, our data indicates that the arsenite induced aggregates post kinase inhibitor treatment are more accumulated in mother cells compared to the buds. This bimodal behavior may simply be a result of lower abundance of Fps1 in the plasma membrane of buds, different Hog1 to Fps1 protein expression ratios in buds compared to mother cells or higher uptake efficiency of inhibitors by mothers compared to buds. It can also be in line with the earlier observation where asymmetric inheritance of oxidatively damaged proteins and their accumulation in mother cells was reported to guarantee the fitness of newly born cells [57]. Previously, it has been shown that the otherwise cytosolic evenly distributed Hsp104-GFP redistributes to distinct foci, proved to be sites of protein aggregates [33]-[35]. Arsenite interferes with protein folding, induces protein aggregates and Hsp104 co-sediments with arsenite induced protein aggregates [33]. This complex here called as Hsp104-GFP aggregates seems to be asymmetrically distributed between mother and daughter cells, which might also be a way to provide fitness to the buds.

\section{Conclusion}

Arsenic carcinogenicity's accumulation in crops and entering the food chain as a global threaten for human 


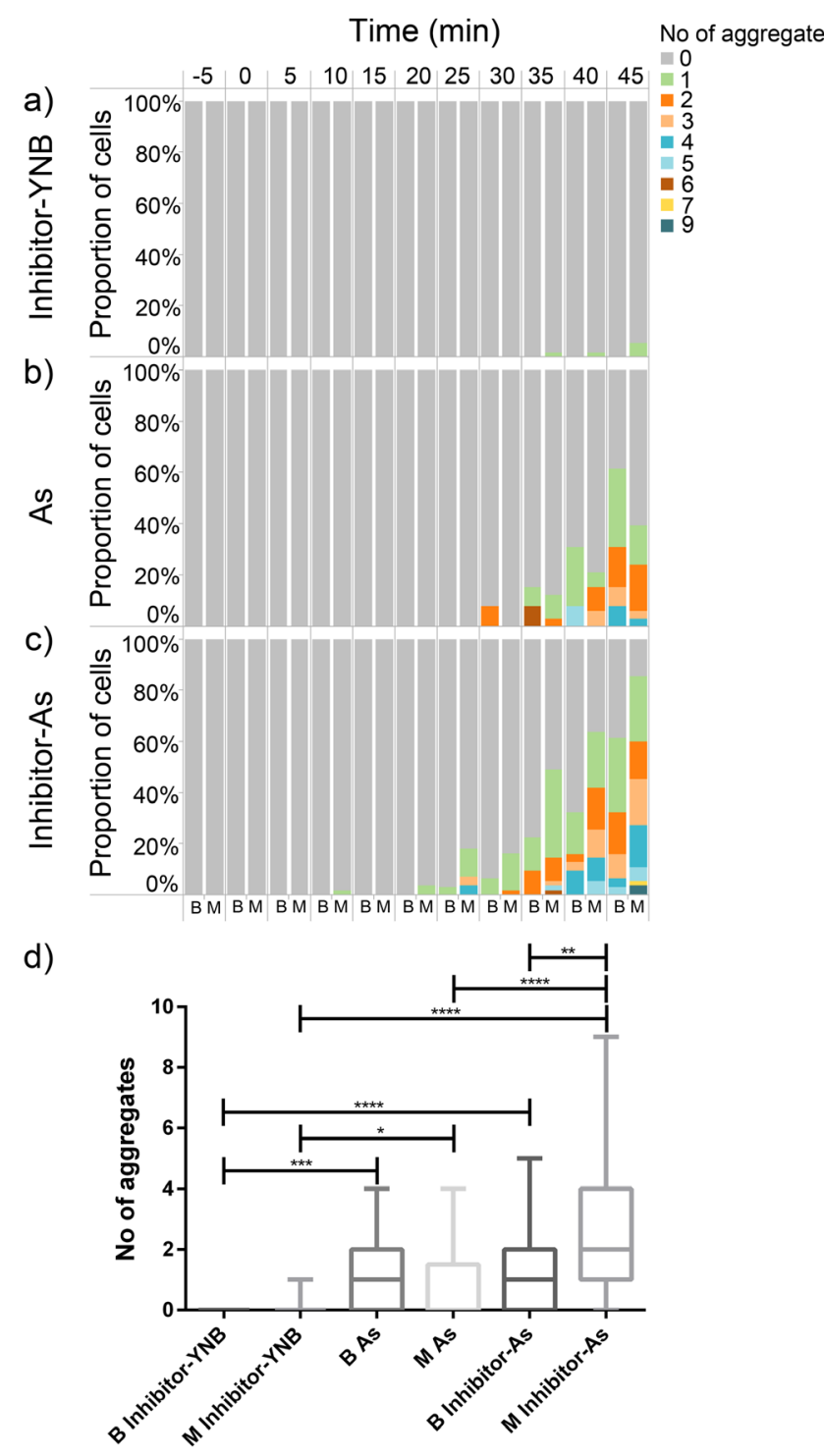

Figure 5. Arsenite accumulates to a higher degree in mother cells compared to their daughters. The percentage of mother cells (M) and buds (B) displaying the distribution of aggregates upon different treatments in a four-inlet microfluidic flow chamber over time. (a) The inhibitor treatment per se (Inhibitor-YNB) does not induce any aggregation in neither buds (28 cells) nor mother cells (54 cells). While the number of aggregates at 45 minutes does not show dramatic difference between mothers (33 cells) and buds (13 cells) upon treatment with $0.1 \mathrm{mM}$ arsenite (As) (b), this difference is slightly more pronounced in the combined inhibitor, sodium arsenite (Inhibitor-As) treatment (55 mother cells vs. 31 daughter cells) (c). In (d), the distribution of aggregates at the final time point is shown in a box plot. The difference between mothers and daughters is only significant at the end of the experiment and only in the condition of sequential arsenite and Hog1 inhibitor treatment. The effect of Hog1 kinase inhibitor in increasing the intracellular levels of arsenite and thereby the number of aggregates is even more significant if this effect is investigated in only mother cells ((b) (mother cells) and (c) (mother cells). The statistics were performed using non-parametric Kruskal-Wallis tests. $\left(^{*}=p<0.05\right)$ 
health [58] on the one hand, and paradoxical application of arsenic-based drugs in modern medical therapy [11] [14] [15] and appearance of resistant cancer cells and parasites [13] [18] [59] on the other hand necessitate the development of approaches in order to tune the arsenite entry into the cells based on purpose. Here, we (to our knowledge) are the first to propose a new approach to increase the cellular arsenite uptake using MAPK inhibitor. This study is first to elucidate that in S. cerevisiae the arsenite uptake (probably through aquaglyceroporin Fps1) can be increased using a selective Hog1 kinase inhibitor. However, this assumption requires further investigations to be proven. The increased arsenite uptake post Hog1 kinase inhibitor treatment compared to only arsenite treatment was reflected both in the number of aggregates per cell (9 compared to 6 respectively), the fraction of the cells showing aggregate ( $80 \%$ compared to $50 \%$ respectively) as well as the initiation time of aggregate formation (30 minutes compared to 20 minutes respectively). Homologs to both MAPK Hog1 and aquaglyceroporin Fps1 are presented in many different organisms e.g. humans and plants, therefore similar approaches may paw the way for environmental and phytoremediation applications as well as for a more effective use of arsenite in medical therapy. As an example, increasing the arsenite uptake through arsenite transporting aquaglyceroporin AtNIP7; 1 in Arabidopsis thaliana [60] by inhibiting the respective MAPK can be an applicable approach to phytoremediate the arsenite contaminated soil and irrigation water around culturing fields. The same approach may hold for increasing the uptake of arsenite through human aquaglyceroporins such as AQP7 and AQP9 to increase the treatment efficacy using arsenic-based chemotherapeutic drugs for acute promyelocyticleukemia [21]. However, extensive, case dependent studies and optimizations are required to step into a larger, applicable level of this approach.

Moreover, we demonstrate a bimodal distribution of arsenite induced aggregates post kinase inhibitor treatment between mother cells and daughter cells as the mean number of aggregates per cell was more pronounced in discriminated mother cells compared to discriminated daughter cells (2.5 vs. 1.2 respectively). Among other possible assumptions, this may be a result of higher arsenite uptake in mother cells compared to buds or a result of asymmetric inheritance of damaged proteins between mother and daughter yeast cells [57]. Alternatively, the rate of protein synthesis in buds compared to mother cells might be another factor affecting the asymmetrical distribution as arsenite seems to primarily target the proteins in the process of synthesis or folding [33]. However, understanding the underlying mechanisms behind this asymmetrical distribution requires further detailed studies.

Collectively, we believe that the presented approach can have great implications in environmental as well as medical and pharmaceutical applications. Besides, detailed understanding the yeasts' "maternal" behavior is per se fascinating.

\section{Acknowledgements}

This work was supported by Carl Trygger Foundation for Scientific Research, Olle Engkvist Byggmästare Foundation, the Swedish research council (VR) and the European Commission program UNICELLSYS. The work was performed at the research facility Centre for Biophysical Imaging, sponsored by the University of Gothenburg. Prof. Markus J. Tamás, Prof. Stefan Hohmann and Peter Dahl are acknowledged for kindly providing the genetically modified yeast strain.

\section{References}

[1] Bhattacharjee, H., Rosen, B.P. and Mukhopadhyay, R. (2009) Aquaglyceroporins and Metalloid Transport: Implications in Human Diseases. Handbook of Experimental Pharmacology, 190, 309-325.

[2] Evens, A.M., Tallman, M.S. and Gartenhaus, R.B. (2004) The Potential of Arsenic Trioxide in the Treatment of Malignant Disease: Past, Present, and Future. Leukemia Research, 28, 891-900.

http://dx.doi.org/10.1016/j.leukres.2004.01.011

[3] Bagchi, S. (2007) Arsenic Threat Reaching Global Dimensions. CMAJ, 177, 1344-1345. http://dx.doi.org/10.1503/cmaj.071456

[4] Liu, S.X., Athar, M., Lippai, I., Waldren, C. and Hei, T.K. (2001) Induction of Oxyradicals by Arsenic: Implication for Mechanism of Genotoxicity. Proceedings of the National Academy of Sciences of the United States of America, 98, 1643-1648. http://dx.doi.org/10.1073/pnas.98.4.1643

[5] Waxman, S. and Anderson, K.C. (2001) History of the Development of Arsenic Derivatives in Cancer Therapy. The Oncologist, 6, 3-10. http://dx.doi.org/10.1634/theoncologist.6-suppl_2-3 
[6] Azizur Rahman, M., Hasegawa, H., Mahfuzur Rahman, M., Mazid Miah, M.A. and Tasmin, A. (2008) Arsenic Accumulation in Rice (Oryza sativa L.): Human Exposure through Food Chain. Ecotoxicology and Environmental Safety, 69, 317-324. http://dx.doi.org/10.1016/j.ecoenv.2007.01.005

[7] Tseng, C.H., Tai, T.Y., Chong, C.K., Tseng, C.P., Lai, M. S., Lin, B.J., Chiou, H.Y., Hsueh, Y.M., Hsu, K.H. and Chen, C.J. (2000) Long-Term Arsenic Exposure and Incidence of Non-Insulin-Dependent Diabetes Mellitus: A Cohort Study in Arseniasis-Hyperendemic Villages in Taiwan. Environmental Health Perspectives, 108, 847-851. http://dx.doi.org/10.1289/ehp.00108847

[8] Meliker, J.R., Wahl, R.L., Cameron, L.L. and Nriagu, J.O. (2007) Arsenic in Drinking Water and Cerebrovascular Disease, Diabetes Mellitus, and Kidney Disease in Michigan: A Standardized Mortality Ratio Analysis. Environmental Health, 6, 4. http://dx.doi.org/10.1186/1476-069X-6-4

[9] Tamas, M.J. and Wysocki, R. (2001) Mechanisms Involved in Metalloid Transport and Tolerance Acquisition. Current Genetics, 40, 2-12. http://dx.doi.org/10.1007/s002940100234

[10] Raju, G.P. (2011) Arsenic: A Potentially Useful Poison for Hedgehog-Driven Cancers. Journal of Clinical Investigation, 121, 14-16. http://dx.doi.org/10.1172/JCI45692

[11] Nok, A.J. (2003) Arsenicals (Melarsoprol), Pentamidine and Suramin in the Treatment of Human African Trypanosomiasis. Parasitology Research, 90, 71-79.

[12] Barrett, M.P., Burchmore, R.J., Stich, A., Lazzari, J.O., Frasch, A.C., Cazzulo, J.J. and Krishna, S. (2003) The Trypanosomiases. The Lancet, 362, 1469-1480. http://dx.doi.org/10.1016/S0140-6736(03)14694-6

[13] Baker, N., De Koning, H.P., Maser, P. and Horn, D. (2013) Drug Resistance in African Trypanosomiasis: The Melarsoprol and Pentamidine Story. Trends in Parasitology, 29, 110-118. http://dx.doi.org/10.1016/j.pt.2012.12.005

[14] Barrett, J. (2003) Allogeneic Stem Cell Transplantation for Chronic Myeloid Leukemia. Seminars in Hematology, 40, 59-71. http://dx.doi.org/10.1016/S0037-1963(03)70043-2

[15] Douer, D., Hu, W., Giralt, S., Lill, M. and Dipersio, J. (2003) Arsenic Trioxide (Trisenox ${ }^{\circledR}$ ) Therapy for Acute Promyelocytic Leukemia in the Setting of Hematopoietic Stem Cell Transplantation. The Oncologist, 8, 132-140. http://dx.doi.org/10.1634/theoncologist.8-2-132

[16] Pettersson, H.M., Pietras, A., Munksgaard Persson, M., Karlsson, J., Johansson, L., Shoshan, M.C. and Pahlman, S. (2009) Arsenic Trioxide Is Highly Cytotoxic to Small Cell Lung Carcinoma Cells. Molecular Cancer Therapeutics, 8, 160-170. http://dx.doi.org/10.1158/1535-7163.MCT-08-0595

[17] Beauchamp, E.M., Ringer, L., Bulut, G., Sajwan, K.P., Hall, M.D., Lee, Y. C., Peaceman, D., Ozdemirli, M., Rodriguez, O., Macdonald, T.J., Albanese, C., Toretsky, J.A. and Uren, A. (2011) Arsenic Trioxide Inhibits Human Cancer Cell Growth and Tumor Development in Mice by Blocking Hedgehog/GLI Pathway. Journal of Clinical Investigation, 121, 148-160. http://dx.doi.org/10.1172/JCI42874

[18] Ralph, S.J. (2008) Arsenic-Based Antineoplastic Drugs and Their Mechanisms of Action. Metal-Based Drugs, 2008, Article ID: 260146. http://dx.doi.org/10.1155/2008/260146

[19] Wysocki, R., Chery, C.C., Wawrzycka, D., Van Hulle, M., Cornelis, R., Thevelein, J.M. and Tamas, M.J. (2001) The Glycerol Channel Fps1p Mediates the Uptake of Arsenite and Antimonite in Saccharomyces cerevisiae. Molecular Microbiology, 40, 1391-1401. http://dx.doi.org/10.1046/j.1365-2958.2001.02485.x

[20] Ma, J.F., Yamaji, N., Mitani, N., Xu, X.Y., Su, Y.H., Mcgrath, S.P. and Zhao, F.J. (2008) Transporters of Arsenite in Rice and Their Role in Arsenic Accumulation in Rice Grain. Proceedings of the National Academy of Sciences of the United States of America, 105, 9931-9935. http://dx.doi.org/10.1073/pnas.0802361105

[21] Liu, Z., Shen, J., Carbrey, J.M., Mukhopadhyay, R., Agre, P. and Rosen, B.P. (2002) Arsenite Transport by Mammalian Aquaglyceroporins AQP7 and AQP9. Proceedings of the National Academy of Sciences of the United States of America, 99, 6053-6058. http://dx.doi.org/10.1073/pnas.092131899

[22] Bhattacharjee, H., Carbrey, J., Rosen, B.P. and Mukhopadhyay, R. (2004) Drug Uptake and Pharmacological Modulation of Drug Sensitivity in Leukemia by AQP9. Biochemical and Biophysical Research Communications, 322, 836-841. http://dx.doi.org/10.1016/j.bbrc.2004.08.002

[23] Thorsen, M., Di, Y., Tangemo, C., Morillas, M., Ahmadpour, D., Van Der Does, C., Wagner, A., Johansson, E., Boman, J., Posas, F., Wysocki, R., Tamas, M.J. and Boone, C. (2006) The MAPK Hog1p Modulates Fps1p-Dependent Arsenite Uptake and Tolerance in Yeast. Molecular Biology of the Cell, 17, 4400-4410. http://dx.doi.org/10.1091/mbc.E06-04-0315

[24] Hohmann, S. (2009) Control of High Osmolarity Signalling in the Yeast Saccharomyces cerevisiae. FEBS Letters, 583, 4025-4029. http://dx.doi.org/10.1016/j.febslet.2009.10.069

[25] Hohmann, S., Krantz, M. and Nordlander, B. (2007) Yeast Osmoregulation. Methods in Enzymology, 428, 29-45. http://dx.doi.org/10.1016/S0076-6879(07)28002-4 
[26] Brewster, J.L., De Valoir, T., Dwyer, N.D., Winter, E. and Gustin, M.C. (1993) An Osmosensing Signal Transduction Pathway in Yeast. Science, 259, 1760-1763. http://dx.doi.org/10.1126/science.7681220

[27] Hohmann, S. (2002) Osmotic Stress Signaling and Osmoadaptation in Yeasts. Microbiology and Molecular Biology Reviews, 66, 300-372. http://dx.doi.org/10.1128/MMBR.66.2.300-372.2002

[28] Westfall, P.J. and Thorner, J. (2006) Analysis of Mitogen-Activated Protein Kinase Signaling Specificity in Response to Hyperosmotic Stress: Use of an Analog-Sensitive HOG1 Allele. Eukaryotic Cell, 5, 1215-1228. http://dx.doi.org/10.1128/EC.00037-06

[29] Diner, P., Veide Vilg, J., Kjellen, J., Migdal, I., Andersson, T., Gebbia, M., Giaever, G., Nislow, C., Hohmann, S., Wysocki, R., Tamas, M.J. and Grotli, M. (2011) Design, Synthesis and Characterization of a Highly Effective Hog1 Inhibitor: A Powerful Tool for Analyzing MAP Kinase Signaling in Yeast. PLoS ONE, 6, Article ID: e20012. http://dx.doi.org/10.1371/journal.pone.0020012

[30] Wurgler-Murphy, S.M., Maeda, T., Witten, E.A. and Saito, H. (1997) Regulation of the Saccharomyces cerevisiae HOG1 Mitogen-Activated Protein Kinase by the PTP2 and PTP3 Protein Tyrosine Phosphatases. Molecular and Cellular Biology, 17, 1289-1297.

[31] Hamngren, C., Dinér, P., Grøtli, M., Goksör, M. and Adiels, B. (2012) Design and Evaluation of a Microfluidic System for Inhibition Studies of Yeast Cell Signaling. Proceedings of SPIE, 8458, 84582K-1. http://dx.doi.org/10.1117/12.929728

[32] Sanchez, Y., Taulien, J., Borkovich, K.A. and Lindquist, S. (1992) Hsp104 Is Required for Tolerance to Many Forms of Stress. EMBO Journal, 11, 2357-2364.

[33] Jacobson, T., Navarrete, C., Sharma, S.K., Sideri, T.C., Ibstedt, S., Priya, S., Grant, C.M., Christen, P., Goloubinoff, P. and Tamas, M.J. (2012) Arsenite Interferes with Protein Folding and Triggers Formation of Protein Aggregates in Yeast. Journal of Cell Science, 125, 5073-5083. http://dx.doi.org/10.1242/jcs.107029

[34] Kawai, R., Fujita, K., Iwahashi, H. and Komatsu, Y. (1999) Direct Evidence for the Intracellular Localization of Hsp104 in Saccharomyces cerevisiae by Immunoelectron Microscopy. Cell Stress \& Chaperones, 4, 46-53.

[35] Lum, R., Tkach, J.M., Vierling, E. and Glover, J.R. (2004) Evidence for an Unfolding/Threading Mechanism for Protein Disaggregation by Saccharomyces cerevisiae Hsp104. Journal of Biological Chemistry, 279, 29139-29146. http://dx.doi.org/10.1074/jbc.M403777200

[36] Eriksson, E., Enger, J., Nordlander, B., Erjavec, N., Ramser, K., Goksor, M., Hohmann, S., Nystrom, T. and Hanstorp, D. (2007) A Microfluidic System in Combination with Optical Tweezers for Analyzing Rapid and Reversible Cytological Alterations in Single Cells upon Environmental Changes. Lab on a Chip, 7, 71-76. http://dx.doi.org/10.1039/b613650h

[37] Sott, K., Eriksson, E., Petelenz, E. and Goksor, M. (2008) Optical Systems for Single Cell Analyses. Expert Opinion on Drug Discovery, 3, 1323-1344. http://dx.doi.org/10.1517/17460441.3.11.1323

[38] Schaber, J., Adrover, M.A., Eriksson, E., Pelet, S., Petelenz-Kurdziel, E., Klein, D., Posas, F., Goksor, M., Peter, M., Hohmann, S. and Klipp, E. (2010) Biophysical Properties of Saccharomyces cerevisiae and Their Relationship with HOG Pathway Activation. European Biophysics Journal, 39, 1547-1556. http://dx.doi.org/10.1007/s00249-010-0612-0

[39] Eriksson, E., Sott, K., Lundqvist, F., Sveningsson, M., Scrimgeour, J., Hanstorp, D., Goksor, M. and Graneli, A. (2010) A Microfluidic Device for Reversible Environmental Changes around Single Cells Using Optical Tweezers for Cell Selection and Positioning. Lab on a Chip, 10, 617-625. http://dx.doi.org/10.1039/b913587a

[40] Petelenz-Kurdziel, E., Eriksson, E., Smedh, M., Beck, C., Hohmann, S. and Goksor, M. (2011) Quantification of Cell Volume Changes upon Hyperosmotic Stress in Saccharomyces cerevisiae. Integrative Biology, 3, 1120-1126. http://dx.doi.org/10.1039/c1ib00027f

[41] Gustavsson, A.K., Van Niekerk, D.D., Adiels, C.B., Du Preez, F.B., Goksor, M. and Snoep, J.L. (2012) Sustained Glycolytic Oscillations in Individual Isolated Yeast Cells. FEBS Journal, 279, 2837-2847. http://dx.doi.org/10.1111/j.1742-4658.2012.08639.x

[42] Babazadeh, R., Adiels, C.B., Smedh, M., Petelenz-Kurdziel, E., Goksor, M. and Hohmann, S. (2013) Osmostress-Induced Cell Volume Loss Delays Yeast Hog1 Signaling by Limiting Diffusion Processes and by Hog1-Specific Effects. PLoS ONE, 8, Article ID: e80901. http://dx.doi.org/10.1371/journal.pone.0080901

[43] Beck, C. and Goksör, M. (2012) Microfluidics in Single Cell Analysis. In: Kelly, R.T., Ed., Advances in Microfluidics, InTech, Morn Hill, 173-192.

[44] Neuman, K.C., Chadd, E.H., Liou, G.F., Bergman, K. and Block, S.M. (1999) Characterization of Photodamage to Escherichia coli in Optical Traps. Biophysical Journal, 77, 2856-2863. http://dx.doi.org/10.1016/S0006-3495(99)77117-1

[45] Liang, H., Vu, K.T., Krishnan, P., Trang, T.C., Shin, D., Kimel, S. and Berns, M.W. (1996) Wavelength Dependence of Cell Cloning Efficiency after Optical Trapping. Biophysical Journal, 70, 1529-1533. 
http://dx.doi.org/10.1016/S0006-3495(96)79716-3

[46] Smedh, M., Beck, C.A., Sott, K. and Goksör, M. (2010) CellStress-Open Source Image Analysis Program for SingleCell Analysis. Proceedings of SPIE, 7762, 77622N-1. http://dx.doi.org/10.1117/12.860403

[47] Fujita, K., Kawai, R., Iwahashi, H. and Komatsu, Y. (1998) Hsp104 Responds to Heat and Oxidative Stress with Different Intracellular Localization in Saccharomyces cerevisiae. Biochemical and Biophysical Research Communications, 248, 542-547. http://dx.doi.org/10.1006/bbrc.1998.9008

[48] Bain, J., Plater, L., Elliott, M., Shpiro, N., Hastie, C.J., Mclauchlan, H., Klevernic, I., Arthur, J.S., Alessi, D.R. and Cohen, P. (2007) The Selectivity of Protein Kinase Inhibitors: A Further Update. Biochemical Journal, 408, $297-315$. http://dx.doi.org/10.1042/BJ20070797

[49] Torres-Quiroz, F., Garcia-Marques, S., Coria, R., Randez-Gil, F. and Prieto, J.A. (2010) The Activity of Yeast Hog1 MAPK Is Required during Endoplasmic Reticulum Stress Induced by Tunicamycin Exposure. Journal of Biological Chemistry, 285, 20088-20096. http://dx.doi.org/10.1074/jbc.M109.063578

[50] Mishra, S., Jha, A.B. and Dubey, R.S. (2011) Arsenite Treatment Induces Oxidative Stress, Upregulates Antioxidant System and Causes Phytochelatin Synthesis in Rice Seedlings. Protoplasma, 248, 565-577. http://dx.doi.org/10.1007/s00709-010-0210-0

[51] Tamas, M.J., Luyten, K., Sutherland, F.C., Hernandez, A., Albertyn, J., Valadi, H., Li, H., Prior, B.A., Kilian, S.G., Ramos, J., Gustafsson, L., Thevelein, J.M. and Hohmann, S. (1999) Fps1p Controls the Accumulation and Release of the Compatible Solute Glycerol in Yeast Osmoregulation. Molecular Microbiology, 31, 1087-1104. http://dx.doi.org/10.1046/j.1365-2958.1999.01248.x

[52] Wysocki, R., Bobrowicz, P. and Ulaszewski, S. (1997) The Saccharomyces cerevisiae ACR3 Gene Encodes a Putative Membrane Protein Involved in Arsenite Transport. Journal of Biological Chemistry, 272, 30061-30066. http://dx.doi.org/10.1074/jbc.272.48.30061

[53] Ghosh, M., Shen, J. and Rosen, B.P. (1999) Pathways of As(III) Detoxification in Saccharomyces cerevisiae. Proceedings of the National Academy of Sciences of the United States of America, 96, 5001-5006. http://dx.doi.org/10.1073/pnas.96.9.5001

[54] Swain, P.S., Elowitz, M.B. and Siggia, E.D. (2002) Intrinsic and Extrinsic Contributions to Stochasticity in Gene Expression. Proceedings of the National Academy of Sciences of the United States of America, 99, 12795-12800. http://dx.doi.org/10.1073/pnas.162041399

[55] Johnston, I.G., Gaal, B., Neves, R.P., Enver, T., Iborra, F.J. and Jones, N.S. (2012) Mitochondrial Variability as a Source of Extrinsic Cellular Noise. PLoS Computational Biology, 8, Article ID: e1002416. http://dx.doi.org/10.1371/journal.pcbi.1002416

[56] Cookson, N.A., Cookson, S.W., Tsimring, L.S. and Hasty, J. (2010) Cell Cycle-Dependent Variations in Protein Concentration. Nucleic Acids Research, 38, 2676-2681. http://dx.doi.org/10.1093/nar/gkp1069

[57] Aguilaniu, H., Gustafsson, L., Rigoulet, M. and Nystrom, T. (2003) Asymmetric Inheritance of Oxidatively Damaged Proteins during Cytokinesis. Science, 299, 1751-1753. http://dx.doi.org/10.1126/science.1080418

[58] Huq, S.M., Joardar, J.C., Parvin, S., Correll, R. and Naidu, R. (2006) Arsenic Contamination in Food-Chain: Transfer of Arsenic into Food Materials through Groundwater Irrigation. Journal of Health, Population, and Nutrition, 24, 305316.

[59] Salerno, M. and Garnier-Suillerot, A. (2003) Resistance to Arsenic- and Antimony-Based Drugs. Bioinorganic Chemistry and Applications, 1,189-198. http://dx.doi.org/10.1155/S1565363303000153

[60] Isayenkov, S.V. and Maathuis, F.J. (2008) The Arabidopsis thaliana Aquaglyceroporin AtNIP7;1 Is a Pathway for Arsenite Uptake. FEBS Letters, 582, 1625-1628. http://dx.doi.org/10.1016/j.febslet.2008.04.022 